\title{
RAPD-SCAR Markers for Genetically Improved NEW GIFT Nile Tilapia (Oreochromis niloticus niloticus L.) and Their Application in Strain Identification
}

\author{
LI Si-Fa*, TANG Shou-Jie, CAI Wan-Qi \\ (Key Laboratory of Aquatic Genetic Resources and Utilizations, Ministry of Agriculture, Shanghai Ocean University, Shanghai 201306, China )
}

\begin{abstract}
The NEW GIFT Nile tilapia (Oreochromis niloticus niloticus L.) is a nationally certificated new strain selected over 14 years and 9 generations from the base strain of GIFT Nile tilapia, introduced in 1994. This new variety has been extended in most of areas of China. The management of genetically improved strains, including the genetic markers for identification is needed urgently. RAPD analysis was conducted and their conversion to SCAR markers was developed. From NEW GIFT Nile tilapia, two strain-specific RAPD bands, $\mathrm{S}_{304}{ }^{624 \mathrm{bp}}$ and $\mathrm{S}_{36}{ }^{568}$ bp were identified. The strain-specific RAPD bands were gel-purified, cloned, and sequenced. Locus-specific primers were then designed to amplify the strain-specific bands. PCR amplification was conducted to test the variations in allele frequencies of two converted SCAR markers among the NEW GIFT Nile tilapia and its base strains, as well as 7 additional farmed strains worldwide. The frequency of SCAR marker I (553 bp) was $85.7 \%$ in NEW GIFT Nile tilapia, but $16.7 \%$ in the base strain. The frequency of SCAR marker II ( $558 \mathrm{bp}$ ) was $91.4 \%$ in NEW GIFT Nile tilapia, but $0 \%-70 \%$ in the 7 other strains. In order to confirm the utility of these two markers, an examination was conducted for a wild population from Egypt, resulted the frequency of SCAR I and II was $10 \%$ and $70 \%$, respectively, much lower than that of New GIFT strain. The increase in allele frequency of these two SCAR markers suggests that these markers might be genetically linked to the quantitative trait loci (QTL) underlining the performance traits by long term selection, and indicate the bright potential of SCAR marker technology for tracking generations during selection progress and for distinguishing among genetically improved strain and other strains.
\end{abstract}

Key words: NEW GIFT; Strain; Nile tilapia; RAPD-SCAR marker; Tracking; Identification

\section{遗传改良“新吉富”（NEW GIFT）尼罗罗非鱼 RAPD-SCAR 标记开发及其在品系鉴别中的应用}

\author{
李思发 ${ }^{*}$, 唐首杰, 蔡完其 \\ （上海海洋大学 农业部水产种质资源与利用重点开放实验室, 上海 201306）
}

摘要: “新吉富”(NEW GIFT)尼罗罗非鱼是以 1994 年引进的“吉富”(GIFT)品系尼罗罗非鱼为基础群体, 经过 14 年 9 代系统选育后获得的新品种, 该品种已被国家审定为良种, 已在全国推广, 迫切需要有效的分子遗传标记 来鉴别该新品种并实施科学管理。该研究对良种群体开展了 RAPD 分析, 并进一步将特异性的 RAPD 标记转化成 了稳定的 SCAR 标记。通过对“新吉富”群体的 RAPD 分析, 找到了两个品种特异性的 RAPD 条带 $\left(\mathrm{S}_{304}{ }^{624} \mathrm{bp}\right.$ 和 $\mathrm{S}_{36}{ }^{568 \mathrm{bp}}$ )。对品种特异性的 RAPD 条带进行了胶回收、克隆和序列测定。根据测序结果设计了两对位点特异性引 物来扩增这两个品种特异性条带（简称 SCAR 标记 I 和 II ）, 检测这两个 SCAR 标记在“新吉富”、“吉富”以及国 内外 7 个养殖品系中的出现频率。SCAR 标记 I (553 bp) 在“新吉富”群体中的出现频率为 $85.7 \%$, 而在其基础群 体 (“吉富”) 中的出现频率仅为 $16.7 \%$; SCAR 标记 II （558 bp）在“新吉富”群体中的出现频率达到 $91.4 \%$, 但在 其它 7 个养殖品系中的出现频率仅在 $0 \% \sim 70 \%$ 之间。为验证这两个标记的可靠性, 检测了这两个标记在一个埃及 罗非鱼野生群体中的出现频率，发现 SCAR 标记 I 和 SCAR 标记 II 的出现频率分别为 $10 \%$ 和 $70 \%$, 远低于在“新 吉富”群体中的出现频率。这两个 SCAR 标记在 “新吉富” 良种群体中的高出现频率, 预示它们可能与生长性能相关

Received date: 2009-08-17; Accepted date: 2010-01-28

Foundation items: National Tilapia Industry Technical System(nycytx-48-3); National Tilapia Seed Program( nyhyzx07-044-01)

收稿日期: 2009-08-17; 接受日期：2009-01-28

*通讯作者(Corresponding author), Tel: +862161900450, E-mail: sfli@shou.edu.cn 
QTL 位点间存在连锁关系，显示 SCAR 标记技术对选育世代间的纵向追溯、以及选育良种群体与其它养殖品系间 的横向鉴别有较好应用前景。

关键词: 新吉富; 品系; 尼罗罗非鱼; RAPD-SCAR 标记; 追溯; 鉴别

中图分类号：Q344.13; Q786;Q959.4 文献标志码：A 文章编号：0254-5853-(2010)02-0147-07

The Genetically Improved Farmed Tilapia (GIFT) Nile tilapia (Oreochromis niloticus) (Eknath et al, 1993; Gupta \& Acosta, 2004), bred by the International Center for Living Aquatic Resources Management (ICLARM; now the WorldFish Center) and its partners, was introduced into China by Shanghai Fisheries University (now Shanghai Ocean University) in 1994. A series of evaluation studies in China from 1994 to 1996 indicated that the GIFT strain exhibited higher growth performance and seinability than previously introduced Nile tilapia strains/lines ( $\mathrm{Li}$ et al, 1998; Li et al, 1999). Therefore, the GIFT strain has been certified and promoted by the Agriculture Ministry of China (Li \& Li, 2001). However, because the introduced GIFT tilapia was only the third generation in 1994 produced by cross-breeding, genetic stability had not yet been achieved, leaving opportunity for further selection. Since 1996, the "Genetic Selection of Nile Tilapia" project was carried out in the $9^{\text {th }}(1996-2000), 10^{\text {th }}(2001-2005)$ and $11^{\text {th }}(2006-2010)$ National Five-Year Programs, using the GIFT strain of Nile tilapia as a base strain (termed $\mathrm{F}_{0}$, although it was the $3 \mathrm{rd}$ generation selected from the Philippines in 1994). The purpose was to further improve the aquaculture performance of GIFT Nile tilapia. Compared to the base strain, the major improvements of F8 and F9 generations were increased growth by $30 \%$, increased fillet ratio by $5 \%-8 \%$, improved stripe pattern on the caudal fin, and higher genetic purity (Hu et al, 2005; Li et al, 2006; Xie, 2006). It was certified as a super strain by the National Certification Committee of Wild and Bred Varieties in January 2006, renamed as NEW GIFT Nile tilapia, and extended by the Ministry of Agriculture and quickly became the principal strain of tilapia cultured in China.

The sequence characterized amplified region (SCAR) marker is one of the stable markers generally derived from random amplified polymorphic DNA (RAPD), or amplified fragment length polymorphism (AFLP) markers (Liu, 2007a; 2007b). The basic principle is to convert the dominant markers into co-dominant markers to reduce the tedious procedures of RAPD or AFLP analysis. With SCAR markers, analysis is reduced to a simple PCR analysis using PCR primers designed from the sequences of the amplicon of RAPD or AFLP.
Because of its simplicity and low cost, SCAR markers have been widely applied to the identification of aquatic animal germplasm (Liu \& Cordes, 2004; Zhou et al, 2001; Iturra et al, 2001; Klinbunga et al, 2004; Araneda et al, 2005; Zou et al, 2005). The objective of this study was to develop molecular markers for the NEW GIFT tilapia. Here we report the development of two RAPD-SCAR markers associated with genetically improved NEW GIFT Nile tilapia and their application for identifying various strains of Nile tilapia and tracking of genetic changes over long-term selection.

\section{Materials and Methods}

\subsection{Fish samples}

A total of 65 fish samples including 35 samples of NEW GIFT Nile tilapia $F_{10}(N G)$ and 30 samples of GIFT Nile tilapia $\mathrm{F}_{0}(\mathrm{GN}$; the base strain) were collected from the Nanhui Fish Breeding Station of Shanghai Ocean University and the National Tilapia Seed Farm Qingdao. In addition, 20 samples were collected from each of 7 farmed strains of Nile tilapia from different tilapia farms in China [Hainan Genoma tilapia company (HG), Xiamen Luye tilapia farm (XL), Guangxi Fisheries Research Institute (GF), Guangdong Weiye tilapia farm (WY), and Guangdong Zhuhai tilapia farm (ZH)], and Hungary [Egypt strain (ET) and Thailand strain (TL) in Sjarvas tilapia farm]. Thirty samples of wild Nile tilapia were also collected from the Egyptian Aquaculture Center (Cairo, Egypt) for verification of our developed SCAR markers.

A small piece of caudal-fin from each individual was clipped and stored in 95\% ethanol until DNA extraction. A total of 130 10-nucleotide random primers were synthesized (Sangon, Shanghai).

\subsection{Genomic DNA extraction}

Genomic DNA was extracted using a phenolchloroform procedure (Sambrook \& Russell, 2001).

\subsection{RAPD analysis and PCR conditions}

PCR mixtures $(25 \mu \mathrm{L})$ contained $2.5 \mu \mathrm{L} 10 \times \mathrm{PCR}$ buffer $(100 \mathrm{mmol} / \mathrm{L}$ Tris-HCl, $\mathrm{pH} 9.5,500 \mathrm{mmol} / \mathrm{L} \mathrm{KCl}$, $30 \mathrm{mmol} / \mathrm{L} \mathrm{MgCl}_{2}$, and $0.001 \%$ gelatin), $2 \mu \mathrm{L} \mathrm{dNTP}$ mixture $(0.2 \mathrm{mmol} / \mathrm{L}$ each of dATP, dCTP, dGTP, and dTTP), $2 \mu \mathrm{L}$ RAPD primer $(0.2 \mu \mathrm{mol} / \mathrm{L}), 2 \mu \mathrm{L}$ template DNA $(50-150 \mathrm{ng}), 0.5 \mu \mathrm{L}$ Taq DNA polymerase $(1.25$ 
$\mathrm{U})$, and $16 \mu \mathrm{L}$ distilled water. PCR amplification was performed in an Eppendorf Mastercycler programmed for initial denaturation at $94^{\circ} \mathrm{C}$ for $5 \mathrm{~min}, 45$ cycles of denaturation at $94^{\circ} \mathrm{C}$ for $45 \mathrm{~s}$, annealing at $36^{\circ} \mathrm{C}$ for $45 \mathrm{~s}$, extension at $72^{\circ} \mathrm{C}$ for $1 \mathrm{~min} 30 \mathrm{~s}$, and a final extension at $72^{\circ} \mathrm{C}$ for $5 \mathrm{~min}$. Reaction tubes were held at $4{ }^{\circ} \mathrm{C}$ prior to visualization of PCR products in a $1.5 \%$ agarose gel stained with ethidium bromide. Each RAPD assay was performed three times to ensure reproducibility.

\subsection{Cloning and sequencing of strain-specific RAPD amplicons}

All strain-specific RAPD amplicons were excised from agarose gels, and the DNA fragment was recovered using a $3 S$ Spin PCR Product Purification Kit (Biocolor Inc., China) following the manufacturer's protocol. An aliquot of the recovered DNA fragment was reamplified using the corresponding primer to verify that only a single band was excised. The recovered DNA fragment was then ligated into the pGEM-T Easy Vector (Promega). Then, DH5 $\alpha$ competent cells (TIANGEN) were transformed with ligated DNA following the manufacturer's protocol. In order to detect cloning success, three white colonies were selected from each plate and were screened by PCR using the T7 and Sp6 primers. The cloned fragments were sequenced on an Applied Biosystems ABI 3730 capillary sequencer.

\subsection{SCAR analysis}

The nucleotide sequence of each of the cloned RAPD fragments was used to design pairs of SCAR primers(Tab. 1). PCR mixtures $(25 \mu \mathrm{L})$ contained $2.5 \mu \mathrm{L}$ $10 \times$ PCR buffer $(100 \mathrm{mmol} / \mathrm{L}$ Tris-HCl, $\mathrm{pH} 9.5,500$ $\mathrm{mmol} / \mathrm{L} \mathrm{KCl}, 30 \mathrm{mmol} / \mathrm{L} \mathrm{MgCl}_{2}$, and $0.001 \%$ gelatin), 2 $\mu \mathrm{L}$ dNTP mixture $(0.2 \mathrm{mmol} / \mathrm{L}$ each of dATP, dCTP, $\mathrm{dGTP}$, and dTTP), $1 \mu \mathrm{L}$ of forward primer $(0.2 \mu \mathrm{mol} / \mathrm{L})$, $1 \mu \mathrm{L}$ of reverse primer $(0.2 \mu \mathrm{mol} / \mathrm{L}), 2 \mu \mathrm{L}$ template DNA (50 -150 ng), $0.5 \mu \mathrm{L}$ Taq DNA polymerase (1.25 U), and $16 \mu \mathrm{L}$ distilled water. The amplification profile was for 5 min of initial denaturation at $94^{\circ} \mathrm{C}, 35$ cycles of denaturation at $94^{\circ} \mathrm{C}$ for $30 \mathrm{~s}$, annealing at $57^{\circ} \mathrm{C}$ for $45 \mathrm{~s}$, extension at $72^{\circ} \mathrm{C}$ for $1 \mathrm{~min}$, and a final extension at 72 ${ }^{\circ} \mathrm{C}$ for $10 \mathrm{~min}$. Reaction tubes were held at $4{ }^{\circ} \mathrm{C}$ prior to visualization of PCR products in a $1.5 \%$ agarose gel stained with ethidium bromide.

\subsection{Verification}

Thirty samples of wild Egypt Nile tilapia were tested for verification of the developed SCAR markers.

\section{Results}

\subsection{SCAR I}

2.1.1 RAPD amplification results RAPD analysis was performed on 10 genomic DNA samples of selected strains and base strains by using fifty 10-nucleotide random primers. Of these 50 primers, 23 showed both stable amplification and polymorphism. There was only one specific band between the two groups, $\mathrm{S}_{304}{ }^{624}$ bp; this fragment served as a specific marker distinguishing the selected strain from the base strain. The $624 \mathrm{bp}$ band amplified by $\mathrm{S}_{304}$ primer is shown in Fig. 1.

2.1.2 Development of SCAR markers The $\mathrm{S}_{304}{ }^{624}$ bp fragment was recovered, cloned and sequenced. The sequence of the $\mathrm{S}_{304}{ }^{624}$ bp fragment is shown in Fig. 2. Both the $20 \mathrm{bp}$ forward primer and $21 \mathrm{bp}$ reverse primer were designed according to the $\mathrm{S}_{304}{ }^{624}$ bp sequence

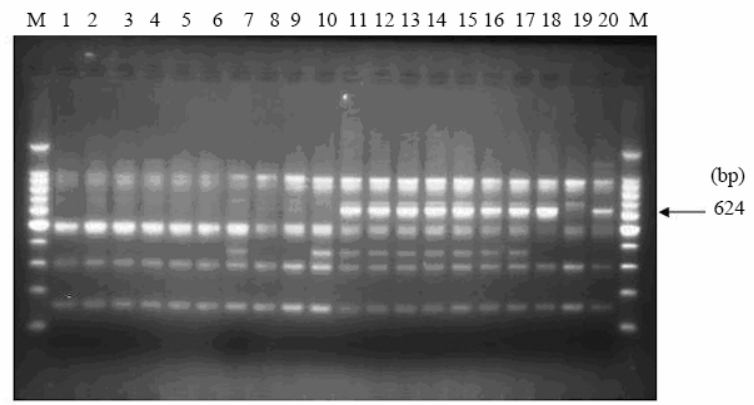

Fig. 1 The amplification results of primer $\mathrm{S}_{304}$ (CCGCTACCGA) in NEW GIFT strain and base strain 1-10: base strain $\left(\mathrm{F}_{0}\right)$; 11-20: NEW GIFT $\left(\mathrm{F}_{10}\right)$; M: 100 bp DNA ladder.

Tab. 1 Primer sequence, annealing temperature and size of PCR band of SCAR markers I and II

\begin{tabular}{|c|c|c|c|c|}
\hline $\begin{array}{l}\text { RAPD } \\
\text { primer }\end{array}$ & $\begin{array}{c}\text { RAPD marker } \\
\text { (bp) }\end{array}$ & SCAR primer sequence & $\begin{array}{l}\text { Annealing temperature } \\
\qquad\left({ }^{\circ} \mathrm{C}\right)\end{array}$ & $\begin{array}{c}\text { Size of PCR band } \\
\text { (bp) }\end{array}$ \\
\hline \multicolumn{5}{|l|}{ SCAR I } \\
\hline \multirow[t]{2}{*}{$\mathrm{S}_{304}$} & 624 & 5' -GGTGCCTTTTGAATGAGCTA-3' & 57 & 553 \\
\hline & & $5^{\prime}$-TGAGATACTGCTACAGCGTGA-3' & & \\
\hline \multicolumn{5}{|l|}{ SCAR II } \\
\hline \multirow[t]{2}{*}{$\mathrm{S}_{36}$} & 568 & $5^{\prime}-$ TGGATGGATGGATTGATGGA - $3^{\prime}$ & 57 & 558 \\
\hline & & $5^{\prime}$ - AGCCAGCGAACCAAGATCTAT - $3^{\prime}$ & & \\
\hline
\end{tabular}




\section{GTG TAAAGCCTGGGGTGCCTTTTGAATG AGCT AACTCACATTAATT GCGTT GCGCTCCCTCAG CCCGCTT TCTAG CAGG GAAACCT GT CG TG CCAGCTG CAT TAATGAATCG GCCAACGCGCCAGG GG AG AG GCGGTT TGCGTAT TGG GCGC TCTTCCGCTTCCTCGCTCACT GACTCGCTG CG CACTCGG TCGTTCGGCT GC GG CGAGCGG TATC AGCTCACTCAAAGG CGG TAATA CG GT TAT CCACACAG AAT CAGG GG AT AACG CAGG AAAG AACATG TG AGCAAAAG GCCAGCAAAA GG CCAGCAG AACCGT AAAAAG GCCGCGTTG CT GG CG TTTTTCCA TAG GCT CCG CCCCCCT GACG AG CACAT CACAAAAATCGACG CTCAAGT CAGAGGTG GCGAAACCCGACAGG ACTATAAAG AT ACCACAGG CG TTTCCCCCTGGAAG CTCCCTCGTGCGCTCTCCTGTTCCGACC CT GCCGCTTACCGGCAATACCTG TCCG CCTTTCTCCCTTCGGGAAG CGTG GCGCTTTCTCAT AGCTCACGCTGT AGCAGTATCTCAGTTCGGTGTAG GT CGTTCG CT CCAAG CTGG GCTGTGTGC ACG AACCCCCCG TTCAG CC}

Fig. 2 Base sequence of the $\mathrm{S}_{304}{ }^{624 \mathrm{bp}}$ band

The underlined bases show SCAR primer sequence.

(Tab. 1). Due to the GC content in the primer, the location of the primer was not at both ends of the fragment, but located slightly closer to the center of the fragment.

Both samples of the selected strain and base strain were screened with the specific primer. A 553 bp band was produced (Fig. 3 and Fig. 4). The frequency of this 553 bp SCAR marker in selected strains reached $85.7 \%$ (Fig. 3), while the frequency in the base strain was only $16.7 \%$ (Fig. 4). The high frequency of the $553 \mathrm{bp}$ marker can be the criterion for distinguishing NEW GIFT Nile tilapia.

\subsection{SCAR II}

2.2.1 RAPD amplification results RAPD analysis was performed on 10 genomic DNA samples of the NEW GIFT strain and the remaining 7 farmed strains by using eighty 10-nucleotide random primers. Of these 80 primers, 20 showed both stable amplification and polymorphism. There was only one specific band between the two groups, $\mathrm{S}_{36}{ }^{568}$ bp; this fragment served as a specific marker distinguishing the NEW GIFT strain from other strains. The 568 bp band amplified by $\mathrm{S}_{36}$ primer is shown in Fig. 5.

2.2.2 Development of SCAR markers The $\mathrm{S}_{36}{ }^{568}$ bp fragment was recovered, cloned and sequenced. The sequence of the $\mathrm{S}_{36}{ }^{568}$ bp fragment is shown in Fig. 6 .

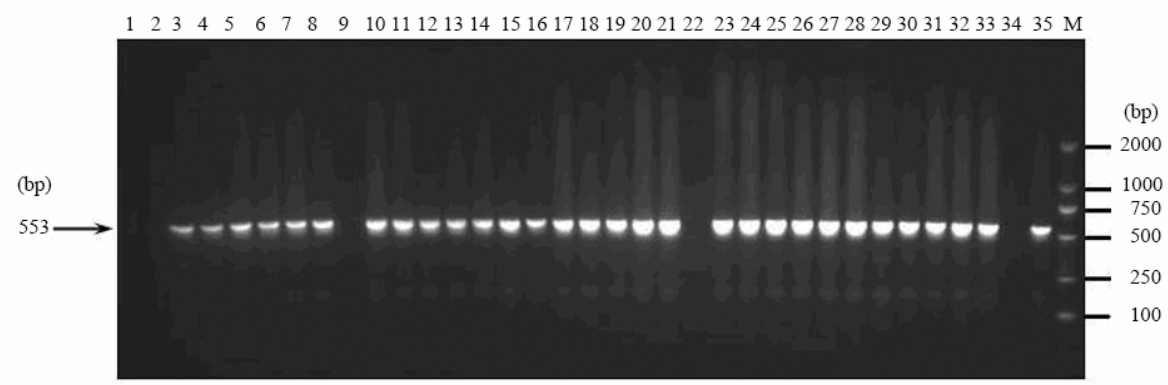

Fig. 3 SCAR band from $\mathrm{S}_{304}{ }^{624 \mathrm{bp}}$ marker in NEW GIFT $\operatorname{strain}\left(\mathrm{F}_{10}\right)$

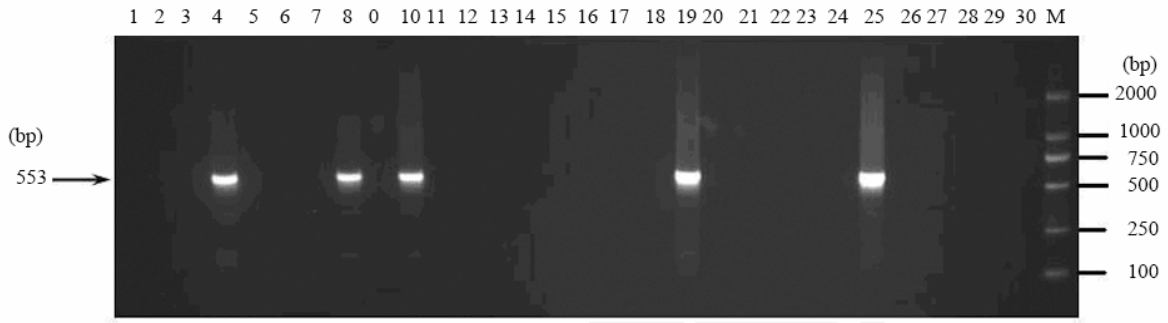

Fig. 4 SCAR band from $\mathrm{S}_{304}{ }^{624 \mathrm{bp}}$ marker in base strain $\left(\mathrm{F}_{0}\right)$ 


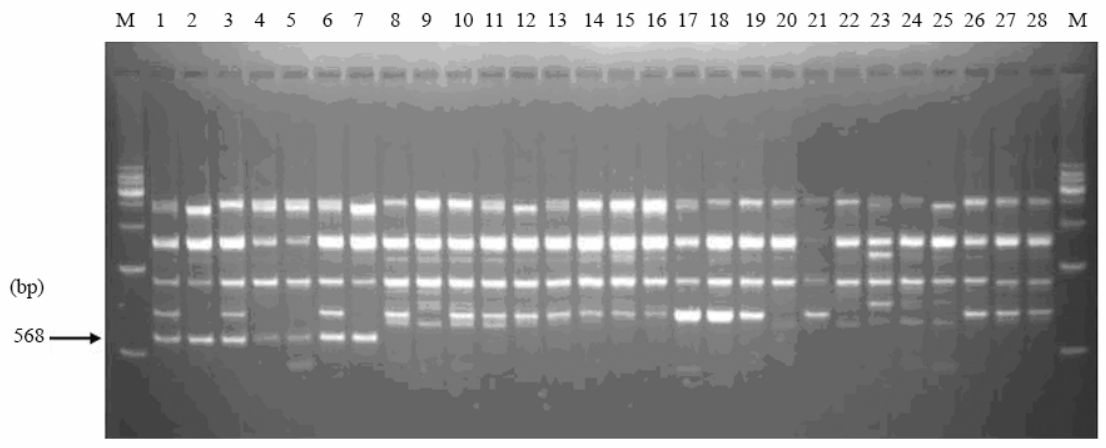

Fig. 5 The amplification results of primer $\mathrm{S}_{36}$ (AGCCAGCGAA) in NEW GIFT strain and 7 other farmed strains of Nile tilapia

1 - 7: NEW GIFT; 8-10: HG; 11 - 13: XL; 14 -16: GF; 17 - 19: ET; 20-22: TL; 23-25: WY; 26 - 28: ZH; M: 500 bp DNA ladder.

\begin{abstract}
AGCCAGCGAATGGATGGATGGATTGATGGATTTATTTTCGTTTTTTCTGCA GTATATAAAAATTG GT GTATCTCAAAAATAAAACTATGAAGACACTCAAA ATAAATTTCCTGTTGTTG TAAACTATTTTTT GCAACTT TTCTATAT TTAAAG TTTTAT ATC TTAAATT TTTCTAAGTAGAAATAT AT GTAAAAAAAAAAAAAA AAAG AAAAGATTTTCAATTTTTTTGTAGTTTATT GCACTTTTTTGCAATTTA TGT AGTTACTATGGACTTAATG CATACATATTATTAAACTTTGGGCTATAA CAG TT GTATTG ATTTATAGTTGAAATG CT CCCAAAAAT GG CACTACAG CAT GTAAAAATATAAAGT AAG CTTGGTTCTATG GT AGGTCTTAAAG GGTTAAA AAG AT AAATGG CT TCTCAGTAG ACCCTCTG CT CAG ATGCCTT GATGAAAT AAG TG CCTG GATGGCTTTGAACT TTTTTACATTTTAATG AG CAGAAAACAG AAG TG ATAGTTTTTG GTGGCG CTTCTGAG ACCACTTCT ATAGATCTTGGTT CGCTGGCT
\end{abstract}

Fig. 6 Base sequence of the $\mathrm{S}_{36}{ }^{568 \text { bp }}$ band

The underlined bases are the SCAR primer sequence.

Both the $20 \mathrm{bp}$ forward primer and $21 \mathrm{bp}$ reverse primer were designed according to the $\mathrm{S}_{36}{ }^{568}$ bp sequence (Tab. 1). Due to the GC content in the primer, the location of the primer was not at both ends of the fragment, but located slightly closer to the center of the fragment.

Thirty five samples of the NEW GIFT strain and 20 samples of each of the 7 farmed strains were screened with the specific primer. A 558 bp band was produced in these two groups. The appearing frequency of this 558 bp SCAR marker in NEW GIFT was 91.4\% (Fig.7), while the frequency in the 7 farmed strains was $70 \%$ (ET), 65\% (HG), 60\% (TL), 55\% (WY), 35\% (XL), 30\%
(ZH)(Fig. 8), and $0 \%$ (GF). The extremely high frequency of the $558 \mathrm{bp}$ marker in NEW GIFT can be used as a criterion for identification of NEW GIFT Nile tilapia.

\subsection{A case of application}

We checked 30 samples of a wild Egyptian population of the Nile tilapia which resulted in a frequency of $10 \%$ by SCAR I and $70 \%$ by SCAR II, which were very coincident with the $70 \%$ in the Egypt strain (ET). This provides evidence for the ability to discern NEW GIFT from other strains.

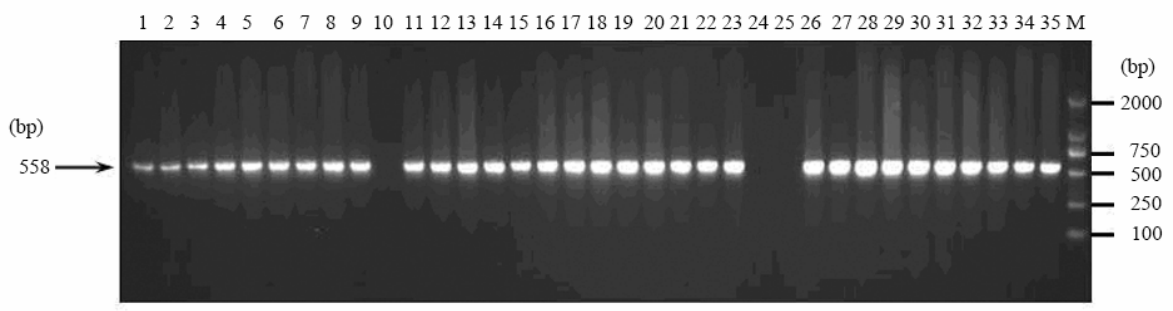

Fig. 7 SCAR band from $\mathrm{S}_{36}{ }^{568 \mathrm{bp}}$ marker in NEW GIFT strain $\left(\mathrm{F}_{10}\right)$ 


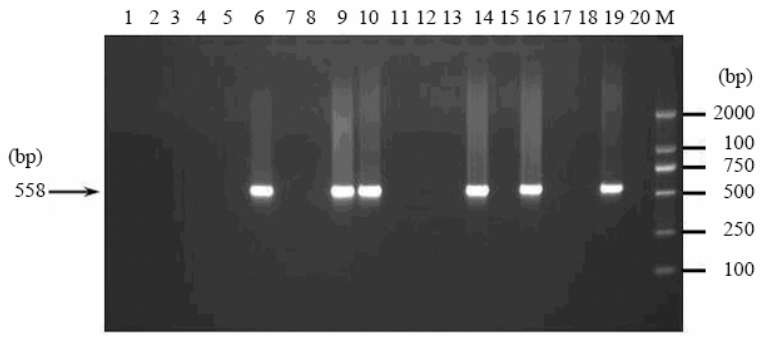

Fig. 8 SCAR band from $\mathrm{S}_{36}{ }^{568 \mathrm{bp}}$ marker in farmed strain of ZH

\section{Discussion}

Through multi-generations of selection, economic traits could be improved and stabilized, and as a result, new strains could be established (Hines, 1976; Lou, 1999). The improved traits could be attributed to natural factors and selection processes that might induce mutations, but the selection itself would not create new genes. However, selection might significantly change the allele frequencies which might cause the change of traits, then the favorable alleles for the traits could be selected.

Breeding requires a long period of time, and how to track the phenotypic variation and genotypic variation of breeding groups is the key to successful breeding. The development of modern molecular genetic technology provides some effective measures for selective breeding. RFLP, RAPD, SSR and SCAR markers are commonly used molecular markers (Liu \& Cordes, 2004). Among them, RAPD needs less DNA template and is relatively easy to operate, but is poor in reproducibility and stability, leading to restrictions in practical application. However, after converting RAPD markers into SCAR markers, the specificity and stability can be greatly improved, which makes it more convenient and efficient in the testing of different alleles.

In this study, two RAPD-SCARs were developed for the NEW GIFT tilapia: firstly checked in the base

\section{References:}

Araneda C, Neira R, Iturra P. 2005. Identification of a dominant SCAR marker associated with colour traits in Coho salmon (Oncorhynchus kisutch)[J]. Aquaculture, 247: 67-73.

Eknath AE, Tayamen MM, Palada-de Vera MS, Danting JC, Reyes RA, Dionisio EE, Capili JB, Bolivar HL, Abella TA, Circa AV, Bentsen HB, Gjerde B, Gjedren T, Pullin RSV. 1993. Genetic improvement of farmed tilapias: the growth performance of eight strains of Oreochromis niloticus tested in different farm environments[J]. Aquaculture, 111: 171-188. strain and 7 other farmed Nile tilapias, and secondly examined in the wild population. The frequency of the 553 bp marker (SCAR I) was up to $85.7 \%$ in NEW GIFT tilapia, significantly higher than the $16.7 \%$ in the base strain, suggesting that this marker can be used to distinguish the selected strain from the base strain. Meanwhile, the frequency of the $558 \mathrm{bp}$ marker (SCAR II) was up to $91.4 \%$ in NEW GIFT, significantly higher than those in the 7 other farmed strains and the wild population $(0 \%-70 \%)$, suggesting its utility in distinguishing NEW GIFT tilapia from other farmed or wild Nile tilapias. They indicate that there is bright potential of SCAR marker technology for tracking generations during selection process and for distinguishing among genetically improved strain and other strains.

When we analyzed the genetic diversity of $\mathrm{F}_{6}, \mathrm{~F}_{7}, \mathrm{~F}_{8}$ and $F_{9}$ of selected GIFT strains, we found that there was a clear trend in genetic purification across generations. The genetic differentiation caused by nine generations of selection was minimal but could be monitored (Xie, 2006). Also, the growth rate increased with selected generations, for example, an average of $4.85 \%$ from F6 to F9. This indicates that the frequency of some alleles related to performance traits significantly changed during the long-term selection process, which implies that there is a correlation between the phenotypic variation and the genotypic variation over the selection period. Such genotype-phenotype associations suggest that the identified markers may be genetically linked to the quantitative trait loci (QTL) underlining the performance traits under selection.

Acknowledgements: We are grateful to Dr. C. H. Wang, Dr. X. Y. Xie, Mr. Y. Zhao for help in molecular analysis, and Mr. Ismail Radwan of the Egyptian Aquaculture Center, Egypt, for help in collecting samples of wild tilapia.

Gupta MV, Acosta BB. 2004. From drawing board to dining table: the success story of the GIFT project[J]. NAGA, World Fish Center Quarterly, 27: 4-14.

Hines NO. 1976. Fish of rare breeding: salmon and trout of the Donaldson strains[M]. Washington, DC: Smithsonian Institution Press, 167.

Hu GC, Li SF, He XJ. 2005. Selective effects of growth from 6th to 8th generation of GIFT strain Oreochromis niloticus[J]. J Shanghai Fisher Univ, 14: 327-331. 
Iturra P, Bagley M, Vergara N. 2001. Development and characterization of DNA sequence OmyP9 associated with the sex chromosomes in rainbow trout[J]. Heredity, 86: 412-420.

Klinbunga S, Amparyup P, Leelatanawit R. 2004. Species identification of the tropical Abalone (Haliotis asinina, Haliotis ovina, and Haliotis varia) in Thailand using RAPD and SCAR markers[J]. J Biochem Mol Biol, 37: 213-220.

Li JL, Li SF. 2001. Introduction and research advances of Oreochromis niloticus in Chinese Mainland[J]. J Fisher, 25: 90-95.

Li SF, Li CH, Li JL. 1998. On-station evaluation of growing performance of five strains of Nile tilapia[J]. J Fisher, 22: 314-321.

Li SF, Li CH, Dey M, Dunham R. 1999. Seinability of four strains of Nile tilapia, Oreochromis niloticus, in Chinese ponds[J]. Aquaculture, 174: 223-227.

Li SF, He XJ, Hu GC, Cai WQ, Deng XW, Zhou PY. 2006. Improving growth performance and caudal fin stripe pattern in selected $\mathrm{F}_{6}-\mathrm{F}_{8}$ generation of GIFT Nile tilapia (Oreochromis niloticus L.) [J]. Aquac Res, 37: 1165-1171.

Liu ZJ. 2007a. Random Amplified Polymorphic DNA (RAPD)[M]//Liu ZJ) Aquaculture Genome Technologies. Ames, IA: Blackwell Publishing, 21-28.
Liu ZJ. 2007b. Chapter 4 Amplified Fragment Length Polymorphism (AFLP)[M]// Liu ZJ. Aquaculture Genome Technologies. Ames, IA: Blackwell Publishing, 29-42.

Liu ZJ, Cordes J. 2004. DNA marker technologies and their applications in aquaculture genetics[J]. Aquaculture, 238: 1-37.

Lou YD. 1999. Fish breeding[M]. Beijing: China Agricultural Publishing House, 10-16.

Sambrook J, Russell DW. 2001. Molecular Cloning: A Laboratory Manual. [M]. $3^{\text {rd }}$ ed. New York: Cold Spring Harbor Laboratory Press.

Xie XY. 2006. A tracking study on the genetic variation during selection of New GIFT strain Nile tilapia (Oreochromis niloticus)[D]. Ph.D. thesis, Shanghai Fisheries University, Shanghai.

Zhou L, Wang Y, Gui JF. 2001. Molecular analysis of silver crucian carp (Carassius auratus gibelio Bloch) clones by SCAR markers[J]. Aquaculture, 201: 219-228.

Zou SM, Li SF, Cai WQ. 2005. SCAR transformation of a RAPD marker in blunt snout bream "Pujiang No.1"[J]. J Fisher Chin, 29: 296-299.

\section{ZOOLOGICAL RESEARCH: Notice to Authors}

1. ZOOLOGICAL RESEARCH deals with all aspects of zoology. Papers on molecular biology and evolution, developmental biology, experimental embryology, biochemistry, physiology, neurobiology, immunology, pathology, genetics, ecology and ethology of animals are especially highlighted. The journal publishes bimonthly peer-reviewed original articles, review articles, research reports, and notes. Papers in English are warmly welcomed.

2. The journal is distributed both home and abroad, and papers are published in either Chinese or English. The journal can be viewed through address: http:/www.zoores.ac.cn/or http://www.wanfangdata.com.cn

3. The submission of a paper for publication indicates that it must not have been published, accepted for publication, or be under consideration for publication wholly or partially elsewhere in any language, i.e. the copyright is transferred from the author to the publisher upon acceptance. Authors may use their article elsewhere after publication provided that prior permission is obtained from the publisher. The authors are responsible for obtaining permission to reproduce copyright material from other sources.

4. Manuscripts and all editorial correspondence compiled with Word document should be e-mailed to zoores@mail.kiz.ac.cn or submitted to http:/www.zoores.ac.cn/, or by a regular mail to the Editorial Office of Zoological Research, Kunming Institute of Zoology, the Chinese Academy of Sciences, 32 Jiaochang Donglu, Kunming, Yunnan 650223, P. R. China. Tel: +86 8715199026 , Fax: +86 8715191823.

5. Title of the paper and the author's names as well as the full address of the corresponding author (detailed address and email address) should appear on the title page. Funding sources should follow as a footnote.

6. Each paper should be preceded by an abstract of no more than 300 words, which summarizes materials and methods, main results, and conclusions. 
7. About five key words for indexing should be provided immediately below the abstract.

8. Headings and subheadings should be listed as “ 1 ” (Materials and Methods), “1.1”, “1.1.1”, “1.2”, “2” (Results), “2.1”, “3” (Discussion), etc.

9. Introduction should summarize the rationale and give a concise background. Use references to provide the most salient background rather than an exhaustive review.

10. Materials and methods provide technical information to allow the fieldwork or experiments to be repeated. Describe new methods or modifications and identify unusual instruments and procedures in detail.

11. Results emphasize or summarize only important observations. Simple data may be set forth in the text without the need of tables and figures.

12. Discussion should deal with the interpretation of your results. Focus the discussion on your results. Emphasize any new and important aspects and relate your results to other studies. End with a brief conclusion.

13. Acknowledgment(s) may briefly include (1) contributors that do not warrant authorship; (2) technical help; and

(3) material support.

14. Tables and figures must be numbered consecutively by Arabic numerals. The captions to illustrations can be bonded with the tables, and the figure legends should be separated from the illustration. Only good drawings and original photographs (ideally as JPEGs or TIFF) suitable for reproduction can be accepted. Actual enlarging multiples or the length unit (bar, in $\mu \mathrm{m}$ or $\mathrm{nm}$ ) should be marked in photos produced by microscopy. Three-line tables (no vertical line appeared) are requested.

15. References to the literature are indicated in the text in the form of "(author's name and year of publication)', e.g. "(Luan et al, 2002)". Listed references should be complete in all details. The full list should be collected and typed at the end of the paper and arranged alphabetically by authors and chronologically for each author as shown below (if originally published in Chinese, followed by the Chinese correspondents).

15.1 For Journal [J]

Luan YX, Xie RD, Yin WY. 2002. Preliminary study on phylogeny of Diplura [J]. Zool Res, 23(2): 149-154.

15.2 For Monographer [M] or Collective works [C]

Gwinner A. 1990. Bird Migration: Physiology and Ecophysiology [M]. Berlin: Springer.

15.3 For a piece in monographer or collective works

Fa JE. 1991. Provisioning of Barbary macaques on the rock of Gibraltar[M] //Box HO. Primate Responses to

Environmental Change. London: Chapman and Hall. 137-154.

16. The corresponding author is invited to return the revision within one month after receiving the reviewers' comments and send the proof back as soon as possible (within three days). 